\title{
ABHAN DLUNGEN
}

DER AKADEMIE DER WISSENSCHAFTEN DER DDR Abteilung Veröffentlichungen der Wissenschaftlichen Räte

Jahrgang $1978 \cdot$ Nr. W 1

22. Tagung des Wissenschaftlichen Rates für die wirtschaftswissenschaftliche Forschung bei der Akademie der Wissenschaften der DDR am 10.6. 1977

\section{Probleme der Leitung in der Wirtschaft}

Zur weiteren Vervollkommnung der Leitung,

Planung und ökonomischen Stimulierung der gesellschaftlichen Produktion; die Entwicklung und Festigung der Kombinate in der sozialistischen Industrie 
Herausgegeben im Auftrage des Präsidenten der Akademie der Wissenschaften der DDR von Vizepräsident Prof. Dr. Heinrich Scheel

Verantwortlich für dieses Heft:

Akademiemitglied Prof. Dr. sc. oec. Helmut Koziolek

Vorsitzender des Wissenschaftlichen Rates für die wirtschaftswissenschaftliche Forschung bei der Akademie der Wissenschaften der DDR

Redaktionsschluß: 10. August 1977

Erschienen im Akademie-Verlag, 108 Berlin, Leipziger Str. 3-4 Akademie-Verlag Berlin 1978

Lizenznummer: $202 \cdot 100 / 34 / 78$

Gesamtherstellung: IV/2/14 VEB Druckerei "Gottfried Wilhelm Leibniz", 445 Gräfenhainichen/ DDR · 5118

Bestellnummer: $7535184(2001 / 78 / 1 / \mathrm{W}) \cdot \mathrm{LSV} 0345$

Printed in GDR

DDR $15,-M$ 